\title{
Photothermal infrared thermography applied to the characterisation of thermal resistances at metal - metal interfaces
}

\author{
by P. Laloue', F. Nigon', S. Offermann², J.- F. Henry², C. Bissieux ${ }^{2}$ \\ ${ }^{1}$ PSA Peugeot Citroën, DPTA/DMTC/MTS/MME, 18 rue des Fauvelles, 92250 La Garenne Colombes; \\ ${ }^{2}$ Laboratoire d'Energétique et d'Optique (UTAP/LEO), UFR Sciences, Moulin de la Housse, BP 1039, \\ 51687 Reims Cedex 2.
}

\begin{abstract}
The quantitative validation of the non destructive testing method begins by comparing the experimental results with a unidimensional multilayer analytical thermal model. Then, the development of an inverse procedure, using the Gauss-Newton parameter estimation method, allows the identification of the thermal resistance or the equivalent air layer thickness at the metal-metal interface. Confidence intervals on these parameters are estimated by this inverse procedure. A unidimensional numerical thermal model by finite differences as well as a tridimensional numerical model by finite elements have been tested. Finally, thermal resistance estimations are presented.
\end{abstract}

\section{Introduction}

Methods allowing for non destructive evaluation of materials are consistently upgraded and their respective industrial applications are increasing. Some metrological developments involve thermal transfers, for which measurements often take place in strenuous conditions of accessibility, such as when attempting to identify thermal resistances of interfaces [1].

The current trend for non destructive testing leads namely to thermal non destructive evaluation of materials associated with inverse methods [2]. The present work, in agreement with this research orientation, aims to characterise the variable thermal resistances occurring at the interface between liners and engine blocks and to quantify eventual air layers that could disturb the engine cooling. Since the phenomenon under study is essentially of thermal nature, photothermal infrared thermography appears to be particularly relevant here. In addition, this non destructive technique is not disturbed by surface roughness and allows both excitation and detection to be applied on the same side. However, a thin black paint layer has to be sprayed on the metal part, in order to increase and especially to homogenise its emissivity.

Under a controlled sinusoidal excitation from a set of four light projectors, the thermal response is measured by means of an infrared camera. A numerical lock-in procedure allows a significant improvement of the signal to noise ratio and yields amplitude and absolute phase maps of the periodic thermal field, for modulation frequencies ranging from $0.01 \mathrm{~Hz}$ to a few $\mathrm{Hz}$. This experimental set-up allows the detection of very weak temperature variations on the surface of the mechanical element under investigation. Then, a quantitative characterisation of the thermal resistance becomes available.

The study of contact between two joined metals has been approached in transient mode by the brief signal method [3]. Then, the periodic thermal field use for thermal resistance measurements by means of thermocouples initiated by Saint-Blanquet [4] in 1970, has been extended to measurement by photothermal radiometry. For example, this method enabled to characterise crimped metal tubes [5] or micrometer-thick TiN coatings on steel substrate [6]. 
The first step of this work is to validate the non destructive technique by confronting the experimental results with an analytical thermal model of unidimensional multilayers. Subsequently, these results are compared with those provided by numerical models. Finally, the thermal resistance (or the equivalent air layer thickness) at the metal-metal interface is identified by an inverse procedure using the Gauss-Newton parameter estimation method. The confidence intervals on the parameters are estimated as well through this inverse procedure.

\section{Analytical thermal model of unidimensional multilayers and inverse procedure}

The thermal phenomenon modelling is realised by an analytical model of unidimensional multilayers represented on figure 1 . This modelling allows to simulate the sample response to a periodic excitation and to obtain the phase and amplitude theoretical values of the front surface temperature response.

An equivalence has already been established between a model considering a two-layer structure with thermal resistance and a second model considering a three-layer structure where a central air layer is located at the interface [5]. Similar results were obtained here in the presence of an additional layer representing the paint coating at the front surface.

A sensitivity study to the different parameters of the model allowed to accurately determine the optimal experimental conditions for air layer detection at the metal-metal interface and the key parameters for subsequent development of the inverse procedure.

The parameters used in the simulations have the following values :

Thickness (m)

Thermal conductivity $\left(\mathrm{W} \cdot \mathrm{m}^{-1} \cdot \mathrm{K}^{-1}\right)$

Density $\left(\mathrm{kg} \cdot \mathrm{m}^{-3}\right)$

Specific heat $\left(\mathrm{J} \cdot \mathrm{kg}^{-1} \cdot \mathrm{K}^{-1}\right)$

Surface exchange coeff. $\left(\mathrm{W} \cdot \mathrm{m}^{-2} \cdot \mathrm{K}^{-1}\right)$

Black paint
$4010^{-6}$
0.36
1000
2000
25

Cast iron
$210^{-3}$
47.3
6987
525

The important sensitivity to the black paint thickness has to be pointed out : a $5.9^{\circ}$ variation is obtained when the paint thickness varies from 40 to $60 \mu \mathrm{m}$ at $0.2 \mathrm{~Hz}$ in a configuration of a perfect contact. Thus, the uniformity of the paint deposit must be controlled.

Figure 2 represents the phase evolution, versus modulation frequency, for different values of the contact thermal resistance. A value of $\mathrm{Rc}=10^{-2} \mathrm{~K} \cdot \mathrm{m}^{2} \cdot \mathrm{W}^{-1}$ induces a phase shift of $27.1^{\circ}$ when compared to the perfect contact at a frequency of $0.2 \mathrm{~Hz}$. If the resistance increases beyond $10^{-2} \mathrm{~K} \cdot \mathrm{m}^{2} \cdot \mathrm{W}^{-1}$, the phase shift remains nearly identical to that obtained without the aluminium plate. Thus, the photothermal method appears to be particularly sensitive, in this case, to values of resistance between $10^{-5}$ and $10^{-2} \mathrm{~K} . \mathrm{m}^{2} . \mathrm{W}^{-1}$.In this range, the sensitivity is indeed $10^{-5} \mathrm{~K} \cdot \mathrm{m}^{2} \cdot \mathrm{W}^{-1}(0.3 \mu \mathrm{m}$-thick air layer) for a phase shift of 1 degree.

The inverse procedure developed, based on the 1D analytical direct model, uses the Gauss-Newton parameter estimation method. The best adjustment with the experimental data provides a thermal resistance estimation as well as a confidence interval on this estimated parameter.

\section{Numerical models}

A finite difference model has been developed, discretizing the unidimensional heat equation according to the Cranck-Nicholson scheme. 
A finite element software (ABAQUS) has been used, firstly for comparison with the preceding analytical and numerical unidimensional calculations [7]. The finite element software especially enables the modelling of 2D located defects accounting for the side diffusion of heat.

Figure 3 compares the results obtained by the two types of numerical modelling with those obtained by the analytical thermal model in the case of a $85 \mu \mathrm{m}$-thick air layer.

\section{Validation of the experimental set-up on thermally thin sample}

Figure 4 illustrates the experimental set-up developed by PSA. Four projectors realise an almost uniform sinewave excitation. An infrared camera AGEMA $900 \mathrm{LW}$ and a numerical lock-in procedure allow the acquisition and post-treatment of the thermosignal images with a significant improvement of the signal to noise ratio. This ratio increases nearly as the square root of the accumulated images number.

The thermal resistance is characterised here starting from the phase of the temperature response which is less affected than the amplitude by the inhomogeneousness of the illumination or by the local variations of optical absorption or emissivity [8].

As a first step of validation of the experimental set-up, the behaviour of a thermally thin material is studied. It is made of a $12 \mu$ m-thick aluminium foil painted in black.

Figure 5 represents the phase experimental evolution for frequencies ranging from $0.01 \mathrm{~Hz}$ to $2 \mathrm{~Hz}$ compared with the theoretical evolution obtained by the analytical model. The experimental and theoretical phases are overall in accordance. The deviations are greater at low frequencies, resulting from the increasing influence of thermal exchange coefficients.

The inverse procedure applied to the phase experimental values provides an exchange coefficient estimation of $25.2+/-0.8 \mathrm{~W} \cdot \mathrm{m}^{-2} \cdot \mathrm{K}^{-1}$ at the front surface with a black paint coating thickness of $36 \mu \mathrm{m}$.

A $145 \mu \mathrm{m}$-thick aluminium foil allows to identify simultaneously a paint thermal conductivity of $0.366+/-0.040 \mathrm{~W} \cdot \mathrm{m}^{-1} \cdot \mathrm{K}^{-1}$ and an exchange coefficient of $19.3+/-1 \mathrm{~W} \cdot \mathrm{m}^{-2} \cdot \mathrm{K}^{-1}$ at the front surface.

The confidence intervals, resulting only from the theory-experiment adjustment, are estimated with a risk of $10 \%$.

\section{Experimental results on metal plates}

Once the functional installation of the non destructive testing console was completed, our study focused on simple academic samples representative of the interface between liners and engine blocks.

The results have been obtained with series of 300 infrared frames quantized on a 12 bit dynamics (ADDELIE system from ADDITIONAL euro technologies SA). The acquisition time of a series varies from 20 to 200 seconds according to the modulation frequency for an acquisition frequency of $15 \mathrm{~Hz}$.

The sample studied is made of a $2 \mathrm{~mm}$ cast iron plate painted in black. Figure 6 represents the experimental and theoretical phase shifts versus frequency. Their similar evolutions constitute a second validation of the experimental set-up. 
In this configuration with a thermal resistance of $10^{-1} \mathrm{~K} \cdot \mathrm{m}^{2} . \mathrm{W}^{-1}$, the paint thermal conductivity is identified. For a paint coating thickness of $49 \mu \mathrm{m}$ at the front face, the paint thermal conductivity is $0.360+/-0.008 \mathrm{~W} \cdot \mathrm{m}^{-1} \cdot \mathrm{K}^{-1}$.

Then, the same cast iron plate has been joined to a $10 \mathrm{~mm}$ aluminium plate. Figure 7 illustrates the phase evolution as a function of the frequency. The inverse procedure applied to these experimental data provides a thermal resistance of $1.9710^{-3}+/-0.110^{-3} \mathrm{~K} . \mathrm{m}^{2} . \mathrm{W}^{-1}$ (that is a $61.8 \mu \mathrm{m}$-thick equivalent air layer).

\section{Conclusions}

The preliminary results demonstrate that photothermal thermography associated with an inverse procedure is well adapted to a quantitative characterisation of thermal resistance at metal-metal interface.

After the non destructive testing experimental set-up has been validated on a thermally thin material and in the case of a thermal resistance of $10^{-1} \mathrm{~K} \cdot \mathrm{m}^{2} . \mathrm{W}^{-1}$, the quantitative characterisation of the thermal resistance at the cast iron - aluminium interface has been realised with success.

Such results are encouraging for the potential industrial application of the method to the characterisation of the interface between liners and engine blocks.

\section{References}

[1] T. LOULOU, R. ABOU-KHACHFE, J.P. BARDON, "Estimation de la résistance thermique de contact durant la solidification du verre", Int. J. Therm. Sci., 38, 1999, p 984-998

[2] J.B. SAULNIER, J. TAINE, "Quelques enjeux en transferts thermiques", Revue générale de thermique, 37, 1998, p 743-758

[3] M. LAURENT, "Contribution à l'étude des échanges de chaleur au contact de deux matériaux", Thèse d'état, Lyon, 1969

[4] C. SAINT-BLANQUET, "Etude du transfert de chaleur entre deux solides accolés en régime thermique sinusoïdal", Thèse de doctorat, Université de Nantes, 1970

[5] E. VAN SCHEL, M. HEURET, C. BISSIEUX, M. REGALIA, M. EGEE, A. BAILLY, "Résistance thermique de contact entre matériaux métalliques : mesure par radiométrie photothermique. Modélisation, expérimentation et application", Revue générale de thermique, 36, 1992, p 321-331

[6] C. MARTINSONS, "Analyse de revêtements durs par radiométrie infrarouge photothermique : estimation des propriétés thermiques par techniques inverses, application à l'évaluation de l'adhérence", Thèse de doctorat, Université de Reims, 1998

[7] T. BECQUET, "Modélisation numérique d'une méthode de contrôle non destructif par thermographie infrarouge photothermique", Projet de fin d'études, INSA de Rouen, 2000

[8] D. WU, G. BUSSE, "Lock-in thermography for non destructive evaluation of materials", Revue générale de thermique, 37, 1998, p 693-703 


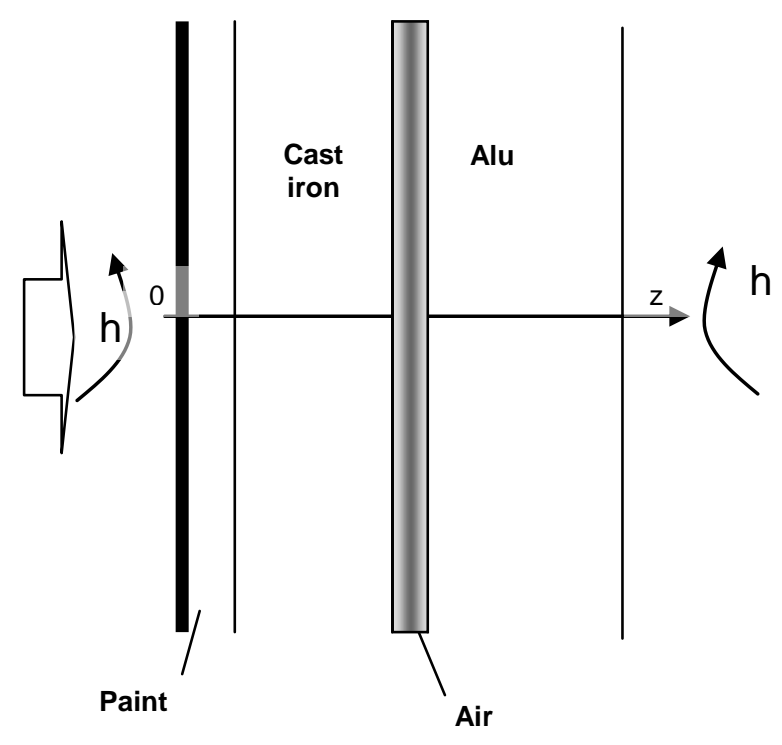

Figure 1 : Four-layer structure

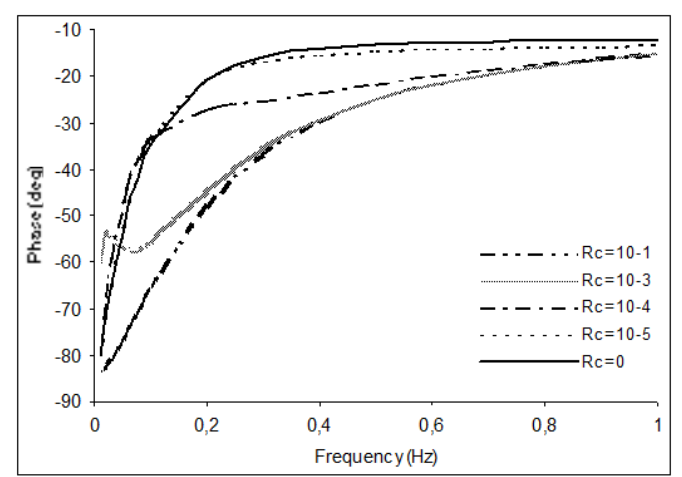

Figure 2 : Theoretical phase shifts versus frequency for different thermal resistance values

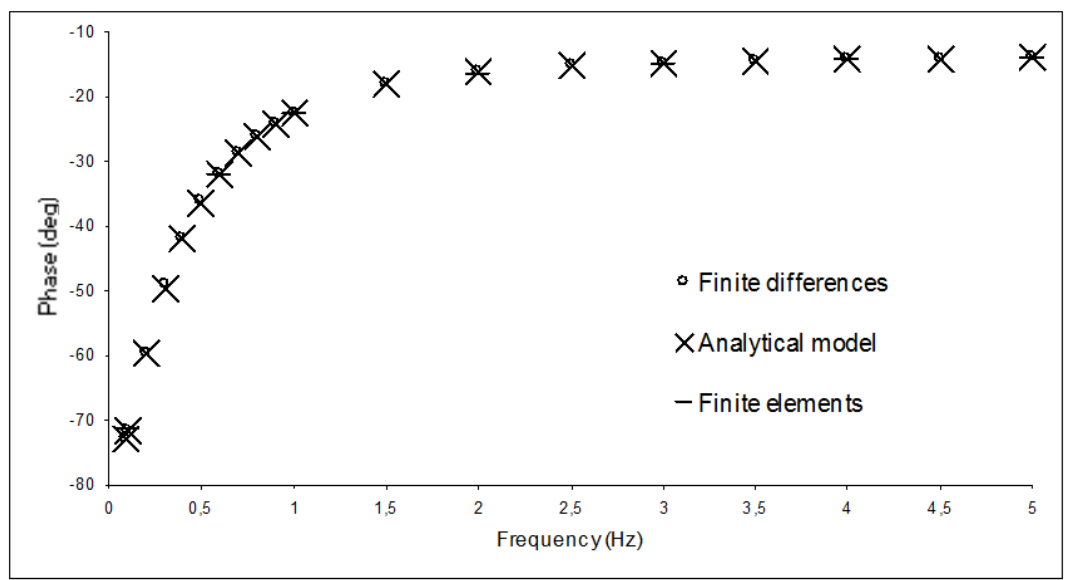

Figure 3: Phase shifts versus frequency calculated with analytical and numerical models

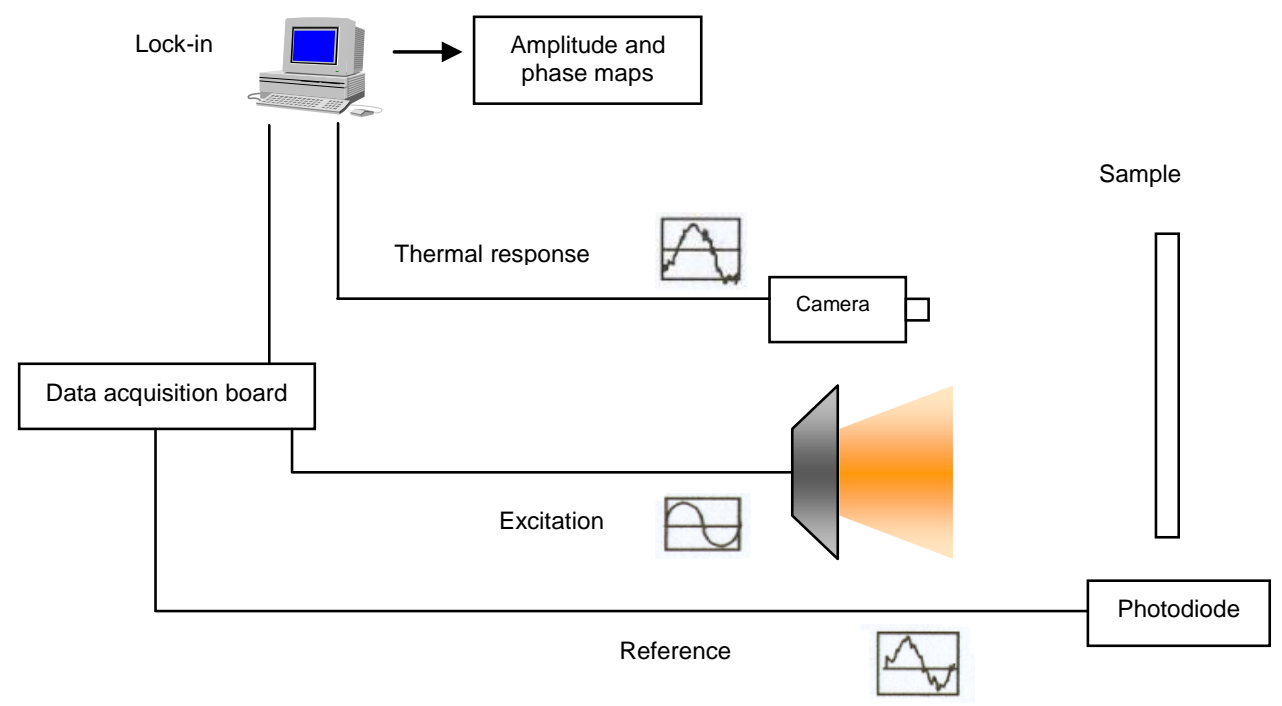

Figure 4: Scheme of the experimental set-up 


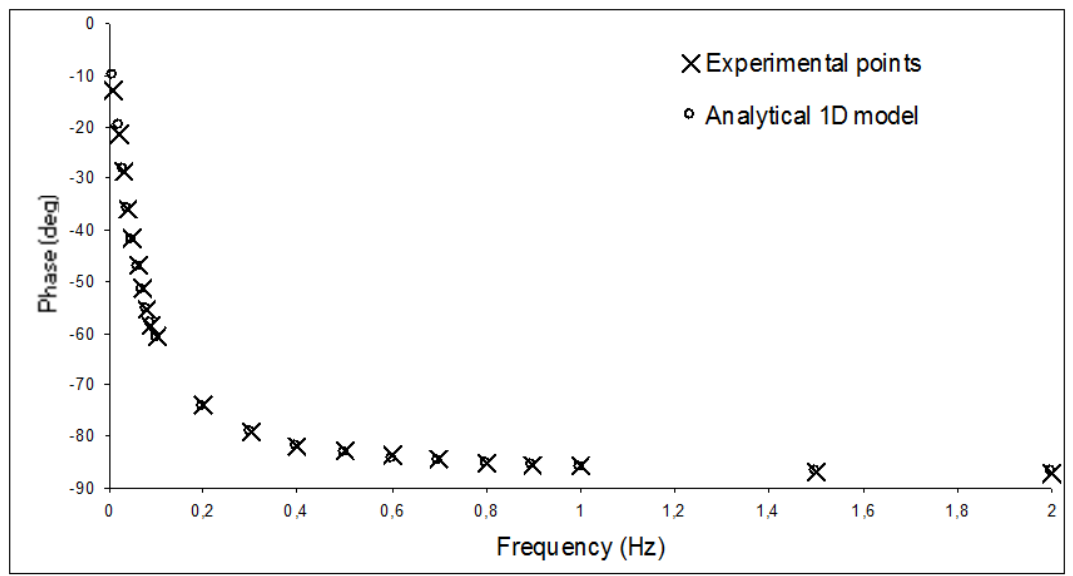

Figure 5 : Experimental and theoretical phase shifts for a thermally thin material

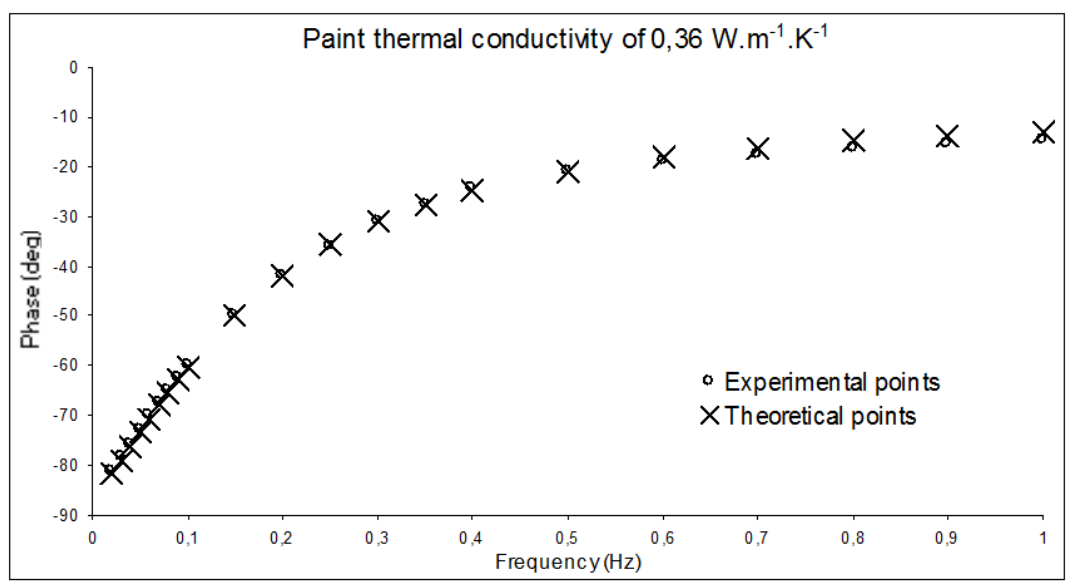

Figure 6: Experimental and theoretical phase shifts for a cast iron plate

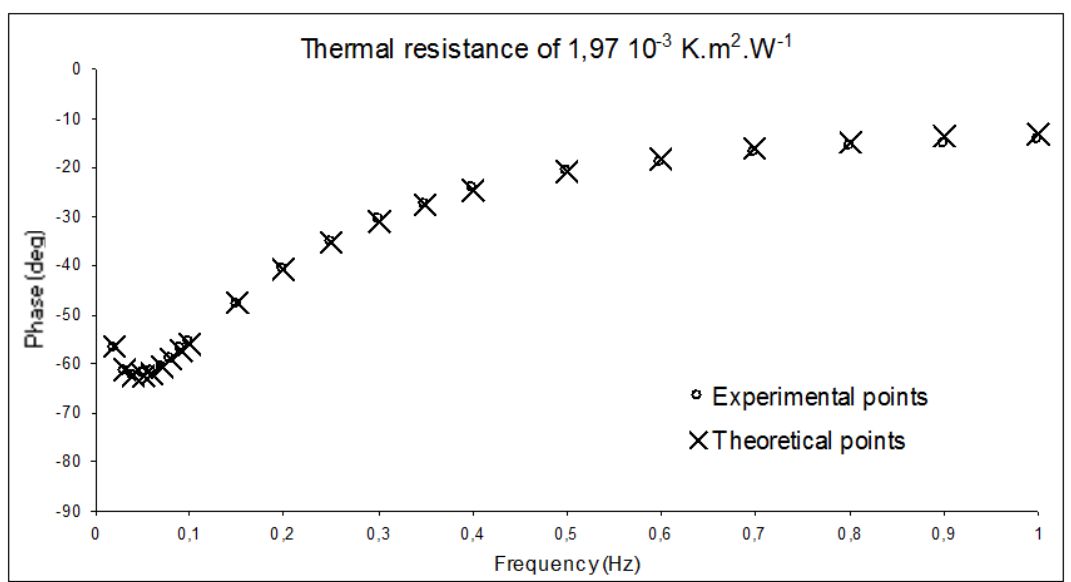

Figure 7: Experimental and theoretical phase shifts for a cast iron - aluminium sample 